\title{
Concurrent Acute Rheumatic Fever and Infective Endocarditis: Case Report
}

\author{
Mecnun Çetin1, Münevver Yilmaz², Yemlihan Ceylan³, Fatoş Alkan², Mahmut Özdemir³, \\ Ersin Gözkeser ${ }^{4}$, Şenol Coşkun ${ }^{2}$ \\ ${ }^{1}$ Pediatric Cardiology, Van Ipekyolu StateHospital, Van, Turkey \\ ${ }^{2}$ Pediatric Cardiology, Celal Bayar University, Manisa, Turkey \\ ${ }^{3}$ Department of Cardiology, Van Educational and Research Hospital, Van, Turkey \\ ${ }^{4}$ Department of Pediatrics, Van Ipekyolu State Hospital, Van, Turkey \\ Email: drmecnun@hotmail.com
}

Received 10 April 2015; accepted 22 May 2015; published 27 May 2015

Copyright (C) 2015 by authors and Scientific Research Publishing Inc.

This work is licensed under the Creative Commons Attribution International License (CC BY).

http://creativecommons.org/licenses/by/4.0/

c) (i) Open Access

\begin{abstract}
Acute rheumatic fever (ARF) is an inflammatory disease that occurs following an infection with certain strains of group A beta-hemolytic streptococci. Despite dramatic falls in the incidence, Acute Rheumatic Fever remains a major cause of morbidity and mortality associated with acquired heart disease in developing countries. Infective endocarditis (IE) is defined as a microbial infection of the endothelial surface of the heart. IE occurs most frequently in patients with chronic rheumatic heart disease. As far as we know, the simultaneous occurrence of both conditions has not been previously reported. References to our outpatient clinic with complaints of fever and joint pain, clinical and laboratory findings suggestive of infective endocarditis fits both with both the ARF and remitted entirely with appropriate treatment, as far as we know, we think that this is not a case of our similar event in the literature. Here we present a case of a fifteen-year-old girl with concurrent acute rheumatic fever and infective endocarditis.
\end{abstract}

\section{Keywords}

Rheumatic Fever, Infective Endocarditis, Heart

\section{Introduction}

Acute rheumatic fever (ARF) is an autoimmune inflammatory disease that occurs following an infection with certain strains of group A beta-hemolytic streptococci. ARF has extremely variable manifestations and remains a clinical syndrome for which no specific diagnostic test exists. Persons who have experienced an episode of ARF 
are predisposed to recurrence following subsequent (rheumatogenic) group A streptococcal infections [1]. Despite dramatic falls in the incidence, rheumatic fever is still an endemic disease in developing countries, and it remains a major cause of morbidity and mortality associated with acquired heart disease in developing countries. Rheumatic heart disease is the most serious manifestation of rheumatic fever. Carditis is the only manifestation of acute rheumatic fever (ARF) that leads to permanent disability [2].

Infective endocarditis (IE) is defined as a microbial infection of the endocardial surface of the heart, which may include one or more heart valves, the mural endocardium, or a septal defect. Its intracardiac effects include severe valvular insufficiency, which may lead to intractable congestive heart failure and myocardial abscesses [3] [4]. Infective endocarditis (IE) is defined as a microbial infection of the endothelial surface of the heart. Infective endocarditis, which is also an important cause of mortality and morbidity, is rare in children [5]. Here, we present a case of a fifteen-year-old girl with concurrent ARF and IE.

\section{Case}

The fifteen-year-old girl patient was admitted to the hospital with fever up to 39 degrees, joint pain and swelling. Five days ago, her left knee was painful and swollen, but before three days it has improved. The joints involved before two days include the right knee and right ankle. On physical examination, the patient's heart rate: 118 beats per minute, respiratory rate: 22 breaths per minute, blood pressure 110/70 mmHg. Heart sounds are tachycardic with a pansystolic murmur 3/6 heard at apex with radiation to axilla. Detailed oral examination revealed two decayed teeth with a poor oral hygiene. Laboratory investigations revealed neutrophilic leukocytosis (WBC $18.100 / \mathrm{mm}^{3}$, N 80\%), elevation of ESR and CRP (106 mm/hr and $132 \mathrm{mg} / \mathrm{dl}$, respectively), elevated streptococcal antibodies (ASO titre $947 \mathrm{U} / \mathrm{mL}$ ) and serum complement $3\left(\mathrm{C}_{3}\right)$ level was normal. The result of other laboratory tests include rheumatoid factor, anti-nuclear antibody (Ab), anti-double-stranded-DNA Ab, and rose bengal tests were all negative. Transthorasic echocardiography (TTE) revealed severe mitral regurgitation and mild aortic regurgitataion. Mitral leaflets were slightly thickened and $10.9 \times 9.3 \mathrm{~mm}$ vegetation was found on anterior leaflet (Figure 1). Viridans group streptococci were isolated from two blood culture samples. The patient was diagnosed with ARF according to the modified Jones criteria, and diagnose of IE was based on modified Duke criteria [6] [7]. Acetyl-salicylic acid therapy at $100 \mathrm{mg} / \mathrm{kg} /$ day was started and continued for eight weeks, and her arthritis was improved dramatically. Intramuscular benzathine penicillin treatment was started, which was given every three weeks for streptococcal prophylaxis. Her symptoms and laboratory data was improved in thirteen days after treatment. The patient also was treated with vancomycin $(40 \mathrm{mg} / \mathrm{kg} / \mathrm{day}$ q $6 \mathrm{~h}$ for 40 days) for IE, and a second echocardiograph confirmed decrease in size of vegetation. However, vegetation was disappeared two months after treatment (Figure 2). The patient is still followed by our pediatric cardiology clinic.

\section{Discussion}

Acute rheumatic fever and rheumatic heart disease continue to be an important cause of cardiovascular morbidity and mortality in the developing world and account for over 30\% of all pediatric cardiac admissions [2]. Acute rheumatic fever, a sequel of group A streptococcal throat infection, occurs in untreated susceptible children and is a multisystem inflammatory disease. The clinical signs of ARF are the same throughout the world. Arthritis is the earliest and the most common feature of the disease, present in $60 \%-80 \%$ of patients. Carditis, the most serious manifestation of the disease, occurs a few weeks after Streptococcus pyogenes throat infection in $30 \%-45 \%$ of ARF patients, and usually presents as pancarditis. Rheumatic endocarditis is the most serious sequel and frequently leads to chronic rheumatic heart disease. Valvular lesionsand mitral and aortic regurgitation are the most common events caused by repeated valvulitis [8] [9]. Acute rheumatic fever (ARF) is diagnosed on the basis of clinical manifestations supported by laboratory tests. The diagnosis of rheumatic fever is based on the Jones criteria [6] (Table 1). Treatment strategies for acute rheumatic fever (ARF) can be divided into management of the acute attack, management of the current infection, and prevention of further infection and attacks. The primary goal of treating an ARF attack is to eradicate streptococcal organisms and bacterial antigens from the pharyngeal region [10].

Infective endocarditis is a microbial infection of the endothelial surface of the heart [11]. According to the Duke criteria, diagnosis of infective endocarditis can be definite, possible, or rejected. A definitive clinical diagnosis is made based on the presence of 2 major criteria, 1 major criteria and 3 minor criteria, or by 5 minor 


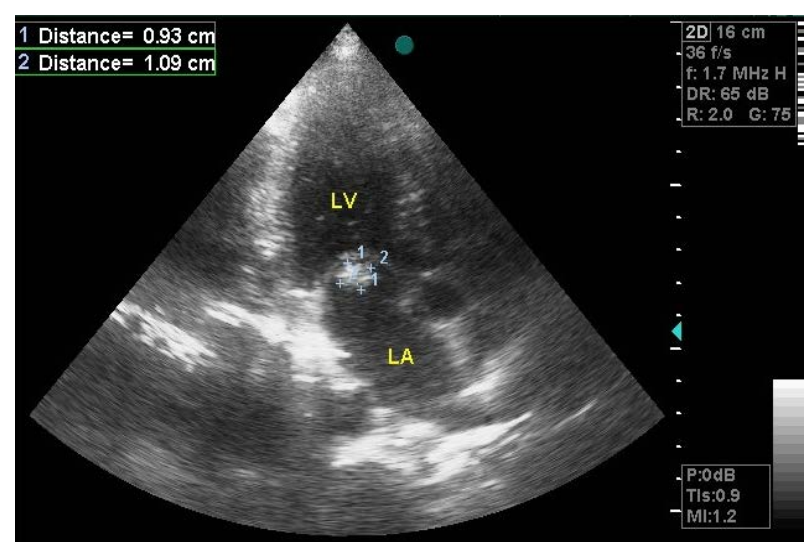

Figure 1. Vegetation on the mitral valve.

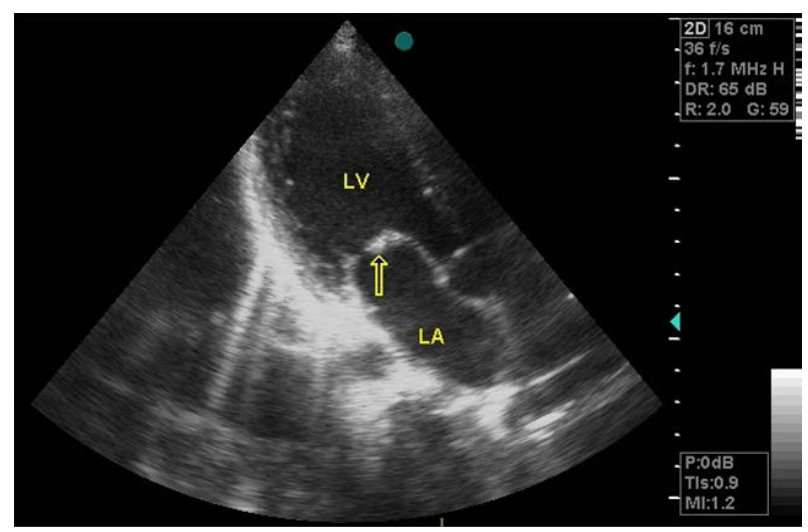

Figure 2. After the treatment of mitral valve.

Table 1. Guidelines for the diagnosis of initial attack of rheumatic fever (Jones Criteria).

\begin{tabular}{|c|c|}
\hline Major manifestation & Minor manifestation \\
\hline Carditis & Fever \\
\hline Migratory polyarthritis & Arthralgia \\
\hline Sydenham's chorea & $\begin{array}{c}\text { Elevated acute phase reactants } \\
\text { (ESR, CRP) }\end{array}$ \\
\hline Subcutaneous nodules & Prolonged PR interval on ECG \\
\hline \multicolumn{2}{|l|}{ Erythema marginatum } \\
\hline \multicolumn{2}{|c|}{$\begin{array}{l}\text { Diagnosis is established if two major or one major + two minor plus } \\
\text { - Supporting evidence of a recent group A streptococcal infection } \\
\text { (positive throat culture or rapid antigen test, elevatedor increasing } \\
\text { streptococcal antibody test) }\end{array}$} \\
\hline
\end{tabular}

criteria. Our patient meets 2 majorcriteria, such as 2 separate positive blood cultures with viridans-group streptococci andevidence of end ocardial involvement with positive echocardiogram. The major goals of therapy for infective endocarditis (IE) are to eradicate the infectious agent from the thrombus and to address the complications of valvular infection. The latter includes both the intracardiac and extracardiac consequences of IE.

Childhood IE was previously only a rare complication of rheumatic heart disease. However, the growing number of patients living with surgical repairs of congenital lesions now represents the majority of patients developing IE in childhood [12]. Despite the improvements in the diagnosis, surgery and medical treatment, IE is 
still a major problem for clinicians and protects its seriousness for mortality rates between 15\% - 20\% [13]-[15]. Therefore, early diagnosis and treatment is critical in saving lives. In our case, appropriate treatment was started immediately after the diagnosis and the patient was recovered completely after the treatment. The patient is being followed up by our pediatric cardiology department with ARF secondary prophylaxis.

In developing countries, IE occurs most frequently in patients with chronic rheumatic heart disease. There is a certain time that elapses between two clinical conditions [16]. To our knowledge the simultaneous occurrence of both conditions has not been previously reported.

\section{Conclusion}

In this case, we reported simultaneous occurrence of IE and ARF. Patients, who had an episode of ARF with high fever and was revealed marked thickening leaflets in echocardiography, should be evaluated carefully for IE. Such patients should be monitored closely with serial echocardiography and blood cultures should be obtained.

\section{References}

[1] Cilliers, A.M. (2006) Rheumatic Fever and Its Management. BMJ, 333, 1153-1156. http://dx.doi.org/10.1136/bmj.39031.420637.BE

[2] Beg, A. and Sadiq, M. (2008) Subclinical Valvulitis in Children with Acute Rheumatic Fever. Pediatric Cardiology, 29, 619-623. http://dx.doi.org/10.1007/s00246-007-9173-0

[3] Brusch, J.L. (2007) Infective Endocarditis and Its Mimics in the Critical Care Unit. In: Cunha, B.A., Ed., Infectious Diseases in Critical Care Medicine, 2nd Edition, Informa Healthcare, New York, 261-262.

[4] Karchmer, A.W. (2005) Infective Endocarditis. In: Zipes, D.P., Libby, P., Bonow, R.O. and Braunwald, E., Eds., Braunwald's Heart Disease: A Textbook of Cardiovascular Medicine, 7th Edition, WB Saunders Co., Philadelphia, 1633-1658.

[5] Saxena, A. (2002) Rheumatic Fever and Long-Term Sequelae in Children. Current Treatment Options in Cardiovascular Medicine, 4, 309-319. http://dx.doi.org/10.1007/s11936-002-0011-7

[6] (1992) Guidelines for the Diagnosis of Rheumatic Fever. Jones Criteria, 1992 Update. Special Writing Group of the Committee on Rheumatic Fever, Endocarditis, and Kawasaki Disease of the Council on Cardiovasvular Disease in the Young of the American Heart Association. JAMA, 268, 2069-2073. http://dx.doi.org/10.1001/jama.268.15.2069

[7] Habib, G., Hoen, B., Tornos, P., Thuny, F., Prendergast, B., Vilacosta, I., Moreillon, P., de JesusAntunes, M., Thilen, U., Lekakis, J., Lengyel, M., Müller, L., Naber, C.K., Nihoyannopoulos, P., Moritz, A., Zamorano, J.L. and ESC Committee for Practice Guidelines (2009) Guidelines on the Prevention, Diagnosis, and Treatment of Infective Endocarditis (New Version 2009): The Task Force on the Prevention, Diagnosis, and Treatment of Infective Endocarditis of the European Society of Cardiology (ESC). European Heart Journal, 30, 2369-2413. http://dx.doi.org/10.1093/eurheartj/ehp285

[8] Carapetis, J.R., McDonald, M.and Wilson, N.J. (2005) Acuterheumatic Fever. The Lancet, 366, 155-168. http://dx.doi.org/10.1016/S0140-6736(05)66874-2

[9] Carapetis, J.R., Steer, A.C., Mulholland, E.K. and Martin Weber, M. (2005) The Global Burden of Group A Streptococcal Diseases. The Lancet Infectious Disease, 5, 685-694. http://dx.doi.org/10.1016/S1473-3099(05)70267-X

[10] Irlam, J.H., Mayosi, B.M., Engel, M.E. and Gaziano, T.A. (2013) A Cost-Effective Strategy for Primary Prevention of Acute Rheumatic Fever and Rheumatic Heart Disease in Children with Pharyngitis. South African Medical Journal, 103, 894-895.

[11] Fink, A.M. (2006) Endocarditis after Valve Replacement Surgery. Early Recognition and Treatment Are Essential to Averting Deadly Complications. AJN, American Journal of Nursing, 106, 40-51. http://dx.doi.org/10.1097/00000446-200602000-00021

[12] Hickey, E.J., Jung, G., Manlhiot, C., Sakopoulos, A.G., Caldarone, C.A.A, Coles, J.G., et al. (2009) Infective Endocarditis in Children: Native Valvepreservation Is Frequently Possible Despite Advanced Clinical Disease. European Journal of Cardiothoracic Surgery, 35, 130-135. http://dx.doi.org/10.1016/j.ejcts.2008.08.020

[13] Tornos, P., Iung, B., Permanyer-Miralda, G., Baron, G., Delahaye, F., Gohlke-Bärwolf, C., et al. (2005) Infective Endocarditis in EUROPE: Lessons from the Euro Heart Survey. Heart, 91 571-575. http://dx.doi.org/10.1136/hrt.2003.032128

[14] Netzer, R.O.M., Zollinger, E., Seiler, C. and Cerny, A. (2000) Infective Endocarditis: Clinical Spectrum Presentation and Outcome. An Analysis of 212 Cases 1980-1995. Heart, 84, 25-30. http://dx.doi.org/10.1136/heart.84.1.25 
[15] Hoen, B., Alla, F., Selton-Suty, C., Béguinot, I., Bouvet, A., Briançon, S., et al. (2002) Changing Profile of Infective Endocarditis. Results of a 1-Year Survey in France. JAMA, 288, 75-81. http://dx.doi.org/10.1001/jama.288.1.75

[16] Cecchi, E., Forno, D., Imazio, M., Migliardi, A., Gnavi, R., Dal Conte, I., et al. (2004) New Trends in the Epidemiological and Clinical Features of Infective Endocarditis: Results of a Multicenter Prospective Study. Italian Heart Journal, 5, 249-256. 